\title{
Silisyum alaşımlı çeliklerde indüklenen anizotropinin manyetik domain yapısına göre incelenmesi
}

\author{
Taylan GÜNEŞ* \\ Yalova Üniversitesi, Enerji Sistemleri Mühendisliği Bölümü, 77100 Yalova/Türkiye \\ Geliş Tarihi (Recived Date): 02.02.2018 \\ Kabul Tarihi (Accepted Date): 18.10.2018
}

\section{Özet}

$\mathrm{Bu}$ çalışmada grainleri yönlendirilmiş $\mathrm{Fe}$-\%3-Si transformatör çeliklerinde, dışarıdan uygulanan manyetik alan yoluyla malzemenin içinde uyarllan anizotropi enerjisi, yüzey domainleri vasitaslyla incelenmiştir. Malzemenin yüzeyindeki bar tipi ve çivi-benzeri manyetik domainler, manyeto-optik Kerr mikroskobuyla görüntülenmiştir. Ayrıca, standart Epstein geometrisine sahip numunelerde, seçili bölgedeki grainlerin kristal yönelimleri, EBSD analiziyle araştırılmış ve Kerr görüntüleriyle karşılaştırılmıştır. Öte yandan, ANSYS benzeşim programıla kare tipi bir transformatör çekirdeğinin eklem bölgelerinde, indüklenmiş anizotropiye bağll akl dăgllımındaki bozulmalar simüle edilmiştir. Böylelikle, enine manyetik alan etkisi altında, yüzey domainlerin vereceği tepkiler ile çeliklerdeki güç kayıpları arasında orantısal bir bağ bulunmuştur. Bir elektrik çeliği ve bu çelikten oluşturulmuş bir transformatör çekirdeğinde oluşan güç kayıplarının bileşenleri, bu orantısal bağ ile hem teorik hem de deneysel olarak karşılaş̧ırılmuştır.

Anahtar kelimeler: Manyetik domain, indüklenmiş anizotropi, elektrik çelikleri, güç kayıplart.

\section{Investigation of induced anisotropy in silicon alloy cores based on magnetic domain structure}

\begin{abstract}
In this study induced anisotropy inside the specimen applying external magnetic field was investigated by means of surface domains in grain-oriented Fe-3\%-Si transformer
\end{abstract}

\footnotetext{
*Taylan GÜNEŞ, taylan.gunes@yalova.edu.tr, https://orcid.org/0000-0002-9543-5482
} 
sheets. Bar (closure)-type domains and lancets on the sheet surface were observed by magneto-optical Kerr microscopy. Moreover, in specimens with standard Epstein geometry, crystal orientations of grains in a chosen spot were examined via EBSD analyses and compared with Kerr images. On the other hand, deterioration in flux density distribution depending on induced anisotropy in the core joints of square-shape transformer was simulated using ANSYS simulation software. Therefore, it is found a proportional connection between the reactions of surface domains under influence of transverse magnetic field and power losses of certain steels. Components of power losses of single steel sheet and of a transformer core made of actual steel sheet have been theoretically and empirically compared with this proportional connection.

Keywords: Magnetic domains, induced anisotropy, electrical steels, power losses.

\section{Giriş}

Genellikle, transformatör, motor ve jeneratörlerdeki çekirdeklerin eklem kısımlarında, akı dağılımı $90^{\circ}$ kadar saptırıldığından dolayı, böyle elektrik makinelerinde, anizotropi enerjisine bağlı ciddi güç kayıpları ve lokal 1sınmalar gözlemlenebilmektedir [1]. Genellikle, (1) ile verilen histerezis kayıplarının $\left(P_{h}\right)$ ve (2) ile verilen klasik girdap akımı kayıplarının $\left(P_{g}\right)$ bağıntıları ile açıklanamayan kayıplar "Anormal Kayıplar" (AK) olarak isimlendirilir [2].

$$
\begin{aligned}
& P_{h}=a \cdot f \cdot B_{\max }^{n}(\mathrm{~W} / \mathrm{kg}) \\
& P_{g}=\frac{\pi \cdot t^{2} \cdot f^{2} B_{\max }^{2}}{6 . \rho . d}(\mathrm{~W} / \mathrm{kg})
\end{aligned}
$$

Burada, $a$ ve $n$ maddeye bağl1 sabitlerdir ve $n$, demir için 1,6 olarak kabul edilen Steinmetz sabitidir. $f(\mathrm{~Hz})$ frekans ve $B_{\max }(\mathrm{T})$ manyetik indüksiyonun en üst değeridir. Ayrıca, $t(\mathrm{~m})$, kullanılan çeliğin kalınlığını, $\rho(\mathrm{ohm}-\mathrm{m})$, elektriksel direnci ve $d\left(\mathrm{~kg} / \mathrm{m}^{3}\right)$ yoğunluğu ifade eder. Malzeme yüzeyinde ve içinde, mıknatıslanma momentlerinin kontrol edildiği, manyetik domainlerin evrilme süreçleri ve domain duvarlarının hareketi, AK'ların bileşenleri hakkında bazı bilgiler sağlayabilir. Ferromanyetik alaşımlı çeliklerin kullanıldığı tüm elektrik makinelerinde, güç kayıpları bileşenlerinden olan, AK görülmesi mümkündür [3]. Ancak, AK'ların, nicel olarak elde edilmesi ve alt gruplarına ayrılması, malzemenin domain yapısının, ayrıntılı olarak görüntülü analiziyle mümkün olabilmektedir [4]. Bu görüntülü analize alternatif olarak histerezis eğrilerindeki diz bölgesi (II. Bölge) de, malzemedeki manyetik moment yönelimini ve dolayısıyla anizotropi kuvvetlerinden kaynaklanacak zorlanmayı nitel olarak belli etse de, nicel bir tanımlama için gerekli olan argümanlar elde edilemez [5]. Bu argümanlardan bazıları, pozitif ya da negatif gerilme etkileri [6], kesme sonucu oluşan saçaklanma ve gerilme etkisi [7], manyetik momentlerden kaynaklanan içyapıda ve yüzeydeki sapmalar [4] ve grain boyutlarındaki farklılaşmalardır [8].

Manyetik domainlerin görüntülü analizi için ise Manyeto-optik Kerr Mikroskobu (MOKE) [4], Taramalı Elektron Mikroskobu (SEM) [9], Geçirmeli Elektron Mikroskobu (TEM) [10] gibi birçok alternatif bulunmaktadır. Manyetik domainlerin görüntülenmesi, grain boyutlarıyla yakından ilgilidir. Bununla birlikte, malzemenin yüzey ve iç kısımlarında bulunan grainlerin yönelim farklılıkları da görüntülemenin 
niteliğini doğrudan etkilemektedir. Bu yönelim farklılıkları, kübik kristal yapısına sahip bir graini-yönlendirilmiş elektrik çeliğinin, grainleri arasında $2^{\circ}-8^{\circ}$ arasında kolay mıknatıslanma ekseninden (KME) sapma şeklinde ortaya çıkar [4]. Ancak, grainleri yönlendirilmemiş silisyum alaşımlı bir çelikte, bu sapma açıları $0^{\circ}-90^{\circ}$ aralığında değişir. Yani bölgesel olarak rastgele bir dağılım söz konusudur. Doğal olarak böyle numunelerde, domain yapısından ziyade grain yöneliminin ve sınırlarının araştırılması daha uygun ve verimli olmaktadır. Yönlendirilmiş çeliklerde ise kübik kristal yapıdaki yönelim diş1 sapmalar, bar domainler içine gömülmüş çivi-benzeri domain yoğunluğundan da, aşağı yukarı anlaşılabilir [11]. Çünkü sapma açıları grainler arasında bile farklılık gösterebilir. Bu durum yerel olarak, depolanan anizotropi enerjisinde farklılıklar oluşmasına sebep olsa da, malzemenin genelinde ortalama bir enerji değerine karşılık gelir.

Genellikle, histerezis eğrilerindeki koersivitenin büyüklüğü, malzemedeki kristal anizotropinin büyüklügüne yorumlanır [12]. Ancak koersivitenin değerine göre nicel olarak doğrudan bir hesap yapmak da mümkün değildir. Bunun yerine, manyeto-optik Kerr görüntüleri yoluyla, yüzey domainlerin manyetik alan etkisi altında, statik görüntüleri üzerinden bir modelleme gerçekleştirilebilir. Bunun için uygulanan MA, $\mathrm{KME}$, bu ikisi arasında oluşan açı değeri, malzemenin anizotropi sabiti ve doyum indüksiyonunun bilinmesi gereklidir. Böylece malzemede depolanan kübik ve birleştirilmiş tek-eksenli anizotropi enerji yoğunluğu,

$E_{a}=K_{0}+K_{1}\left(\alpha_{1}^{2} \alpha_{2}^{2}+\alpha_{2}^{2} \alpha_{3}^{2}+\alpha_{1}^{2} \alpha_{3}^{2}\right)+K_{2}\left(\alpha_{1}^{2} \alpha_{2}^{2} \alpha_{3}^{2}\right)+\cdots$

şeklinde ifade edilebilir. Burada $\boldsymbol{\alpha}_{1}, \boldsymbol{\alpha}_{2}$ ve $\boldsymbol{\alpha}_{3}$, işlem kolaylığı açısından, doyum mıknatıslanması $\left(\mathrm{M}_{\mathrm{s}}\right)$ doğrultusu ile [100], [010] ve [110] eksenleri arasında kalan açının kosinüs değerlerini ifade eder. $\mathbf{K}_{\mathbf{0}}, \mathbf{K}_{\mathbf{1}}$ ve $\mathbf{K}_{\mathbf{2}}$ ise belirli sıcaklıklarda ve belirli malzemeler için tanımlanan, anizotropi sabitleridir. $\mathrm{K}_{0}$, açısal bağımsızlığından dolayı, $\mathrm{K}_{2}$ ise önemsenmeyecek kadar küçük bir terim olduğundan, genellikle ihmal edilir. $\mathrm{Bu}$ bağlamda, KME'ye, $K_{1}$ sabitinin işareti ile karar verilebilir. Doğal olarak, bir malzemede doyum mıknatıslanma ekseni ile haddeleme doğrultusu (HD) arasındaki açı ile depolanan anizotropi enerjisi, teorik olarak hesaplanabilir. [010] doğrultusunda, bir demir kristaline MA uygulandığında, 2-boyutta, [100] ve [110] doğrultularında domain yönelimi kalana dek duvar hareketi devam eder. Böylelikle, malzemedeki $\mathrm{M}_{\mathrm{s}}$, [100] ve [110] doğrultularındaki iki KME arasında, bileşke vektör gibi davranır. Yani her iki doğrultuya da $45^{\circ}$ lik açı yapar. MA'nın daha da arttırılması durumunda, KME'den, $\theta$ açısı kadar uzakta olan $\mathrm{M}_{\mathrm{s}}$ vektörü, uygulanan $\mathrm{MA}$ doğrultusuna gelmeye başlar. $\mathrm{Bu}$ durumda [100] domainleri için, (3) eşitliğindeki $\alpha_{1}, \alpha_{2}$ ve $\alpha_{3}$ doğrultu kosinüsleri, $\alpha_{1}=\cos \theta, \alpha_{2}=\cos (90-\theta)$ ve $\alpha_{3}=0$ olacaktır. Bu durumda, $\mathrm{E}_{\mathrm{a}}$ 'nın yeni formu,

$E_{a}=K_{0}+\frac{K_{1}}{4} \sin ^{2} 2 \theta$

şeklinde ifade edilir. Doyum mıknatıslanması için gerekli olan MA, $\mathbf{K}_{\mathbf{1}}$ 'e bağlı olarak,

$M_{S}=\frac{2 K_{1}}{H}$

ile hesaplanabilir. Bu durumda, malzemenin $\mathrm{KME}$ 'sine bağlı olarak, $\mathrm{M}_{\mathrm{s}}$ değeri de teorik olarak hesaplanabilir. Örneğin, $\mathrm{K}_{1}$ sabiti $4,5 \times 10^{4} \mathrm{~J} / \mathrm{m}^{3}$ ve doyum indüksiyonu 2,14 T olan bir demir parçasının mıknatıslanma eğrisinden, uygulanan MA'nın değeri yaklaşık 
olarak $40 \mathrm{kA} / \mathrm{m}$ olarak bulunabilir. Ancak malzeme, \%3 oranında silisyum eklenmesi ile alaşımlı çelik haline getirilirse, bu değerler, $\mathrm{K}_{1}$ sabitindeki değişime bağlı olarak düşecek ve manyetik geçirgenlikte bir artış olacaktır.

Şekil - 1'de, herhangi bir yüzey içi (in-plane) ve yüzey dışı (out-of-plane) sapma göstermeyen, HD'de uzanmış, bar tipi domainlerden oluşan bir graine uygulanan, enine MA'nın, doyum durumundaki yüzey ve iç mıknatıslanma doğrultuları şematize edilmiştir. Özellikle, kübik kristalik yapıya sahip ferromanyetik alaşımlı çeliklerde, domain yapısı, kristalografik yapının temellerine uygun bir biçimde düşünülmelidir. Öyle ki, Şekil - 1a'da yüzeyde gözlemlenen, ters paralel biçimde dizili manyetik domainlerin, MA şiddetine bağlı olarak, MA doğrultusunda dönmesi oldukça doğal olarak görülebilir. Ancak yüzeyde, [100] doğrultularında, gözlemlenen manyetik moment dağılımları, kübik kristalin diğer eksenleri olan, [010] ve [110] doğrultularıyla da birbirine bağlıdır. Kısacası, uygulanan MA, HD'de 3-boyutlu olarak (birbirlerine dik) dağılmış eksenlerin tümünü, kendi doğrultusuna döndürmek için bir enerji harcayacaktır. $\mathrm{Bu}$ sebeple, uygulanan MA'ya karşı koyan anizotropi kuvvetleri, malzemenin içindeki momentlerin de ciddi manada gerilmelerine sebep olacak ve manyetik gerilme enerjisine $\left(E_{m s}\right)$ bir kaynak oluşturacaktır [13]. Böylelikle, (3)'de verilen açıya bağımlı enerji eşitliği, bu anizotropi kuvvetlerinin, malzemenin yüzeyinde ve içinde depoladığı anizotropi enerjisini ifade eder. Ayrıca bu süreç, alaşımlı bir çeliğin kullanıldığı elektrik makinesinde, AK'nın da nicel hesaplamasına imkân tanır.
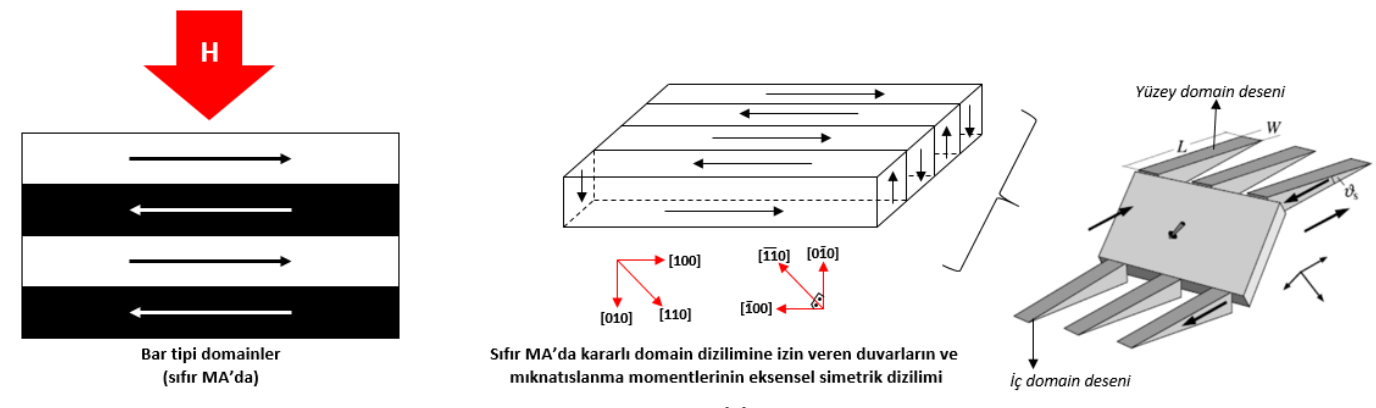
(a)
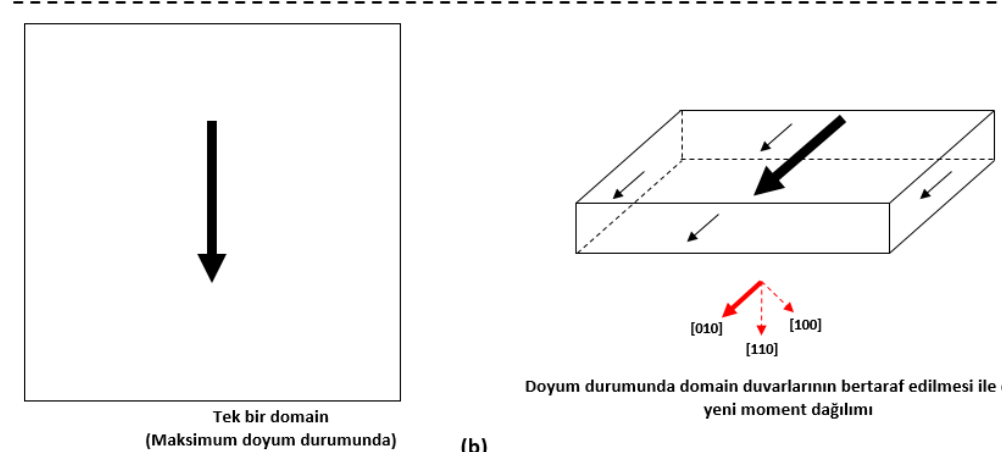

Doyum durumunda domain duvarlarının bertaraf edilmesi ile oluşan yeni moment dağı̆ım

(b)

Şekil 1. Sıfır MA'da (a) ve enine MA (b) uygulamasının, yüzey ve iç domainlerde kübik kristal yapısından dolayı meydana getirdiği değişimler. Sıfır MA'da, yüzey ve iç domain desenlerinin birbirine olan bağımlılı̆̆ı (a)'da üç-boyutlu olarak gösterilmiştir [4].

Manyeto-optik Kerr Etkisi (MOKE) ile yüzey domainlerin, 2-boyuttaki fiziki koşulları statik ve dinamik olarak elde edilebilir $[14,15]$. Bu durumda, iç domainlerin, dahası, domain duvarlarının yönelim ve doğrultularının bulunması, evrilme sürecinin daha yakından takip edilmesine imkân verebilir. Böyle çalışmalar için nötron tarama 
interferometresi adı verilen bir sistem de kullanılmaktadır [16]. Bu çalışma kapsamında, yüzey domainlerin, uygulanan MA etkisi altında yaptığı dönme hareketi, manyetik doyum sağlanana dek aşama aşama incelenmiş ve nicel olarak deneysel verileri ile simülasyon sonuçları karşılaştırılmıştır. Hem grain yapıları hem de domainlerin, kristalografik sapma açıları ile anizotropi enerjileri arasında bir bağıntı kurulmuştur. Ayrıca MOKE gözlemleri ile EBSD analizleri arasında yapılan karşılaştırmalı incelemeler sonucunda, kristalografik yönelimler, MA yoğunluğuna bağlı olarak araştırılmıştır. Araştırmalar sonucunda, yönelim dışı sapma açılarının yoğunluğuna göre malzemelerde oluşan güç kayıplarındaki dağılım gözlemlenebilmiştir.

\section{Deneysel çalışmalar}

Bu çalışmada, $0.3 \times 30 \times 280 \mathrm{~mm}^{3}$ boyutlarında standart Epstein geometrisine sahip \%3SiFe alaşımında, grainleri yönlendirilmiş elektrik çelikleri kullanılmıştır. Numuneler, HD’ye dik kesilmiş yani enine KME'ye sahip çeliklerdir. Kesme işlemleri standart CNC torna tezgâhında gerçekleştirilmiştir. Malzemeler, Kerr mikroskobuyla domain gözlemine uygun hale getirilebilmek için üç aşamalı temizleme prosedürlerine tabii tutulmuştur. Çelikler, üreticiden üzerleri elektriksel olarak inorganik bir yalıtkan ile kaplı halde tedarik edildiğinden dolayı, bu temizleme aşamalarının ilkinde elektrolitik temizlik [4] gerçekleştirilmiştir. Bunun yanı sıra, mekanik temizlik prosedürleri de uygulanmıştır. Mekanik temizlik prosedürleri, en temel haliyle, Kazıma, Taşlama ve Parlatma olarak bilinen 3 aşamalı bir işlemler bütünüdür. Kazıma işleminde numuneler, hidroklorik asit $(\mathrm{HCl})$ içerisine batırılıp bir saat kadar beklendikten sonra uygun bir bez yardımıyla üzerlerindeki kaplamalar sökülmüştür. Taşlama işlemi, kazıma ve parlatma işleminden farklı olarak numuneye fiziksel, katı bir malzemeyle etki etme işlemidir. Bu işlemin temelinde çeşitli sürtünme kuvvetlerine sahip, özel olarak imal edilmiş zımpara kâğıtları üzerinde daireler çizerek malzemenin kaplamasının tamamen çıkarılması ve parlatılması vardır. Parlatma işleminde de çeşitli kimyasalların uygun koşullarda malzemeye nüfuz etmesiyle, numunenin parlak bir yüzeye sahip olması amaçlanmıştır. $\mathrm{Bu}$ işlemlerin ardından malzeme, yüksek çözünürlüklü Kerr mikroskobuyla görüntülenmeye hazır hale getirilmiş olur.

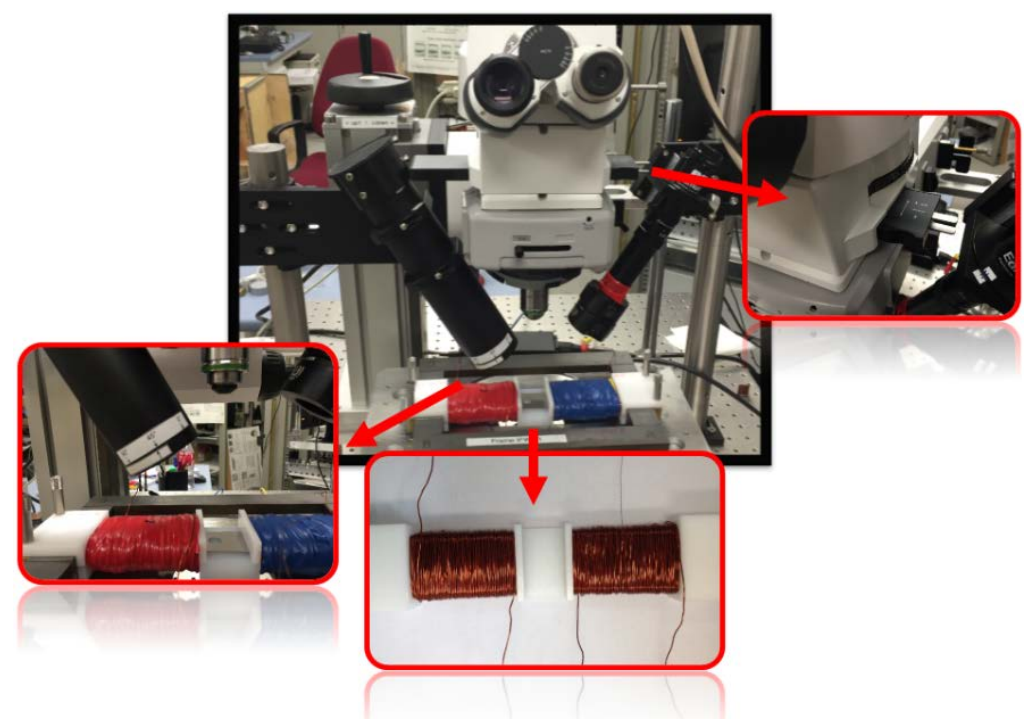

Şekil 2. Kerr mikroskobunun genel görünümü. 
Manyetik domain yapılarının görüntülenmesinde kullanılan Kerr mikroskobunun genel görünümü ve bazı temel ekipmanları şekil - 2'de gösterilmiştir. Burada, malzemeyi mıknatıslamak için özel olarak tasarlanmış $[15,17]$ düzlemsel tek sac ölçüm magnetinin tam orta bölgesinde, $50 \mathrm{~mm}$ uzunluğunda, bir pencere açıklığı bırakılmıştır. 620 sarımlı selenoid bobini içine yerleştirilen numunenin, dinamik olarak görüntülenmesine imkân sağlayan bu pencereden, $0^{\circ}, 45^{\circ}$ ve $90^{\circ}$ lik kutuplanma doğrultularında 1 şık 1 şın 1 gönderilmiş ve parlatılan yüzeyden yansıtılarak, alıcı ekrana gönderilmiştir. Burada kutuplanan 1şı̆̆ın açı değeri KME'ye bağlı olarak ayarlanır. Elde edilen görüntünün kontrast farklılığındaki netlik ise sağ tarafta yakınlaştırılmış görüntüsü verilen analizörün uygun açı değerinde ayarlanmasıyla mümkün olabilmektedir [4].

AC güç kaynağı tarafinda beslenen selenoid bobin ile mıknatıslanan elektrik çeliği üzerine bağlanan arama bobini, LabVIEW ${ }^{\mathrm{TM}}$ programı vasıtasıyla bilgisayar kontrollü olarak yönetilmiştir. İndüklenen manyetik akının, birim zamanda uygulanan MA'nın bir fonksiyonu olarak, lokal ya da genel olarak elde edilmesini sağlamak için malzemenin belirli bölgelerine bağlanan arama bobinleri, çoğaltıcı yoluyla, akı metreye bağlanmıştır. Akı metre de bir devre elemanı olarak ölçme devresinde bilgisayara bağlanmıştır. Tüm kontrol bilgisayardan, manyetik alan ve frekansta yapılan değişimlerle sağlanmıştır ve histerezis eğrileri de bu yolla elde edilmiştir.

\section{Bulgular ve tartışma}

Şekil - 3’te, grainleri yönlendirilmiş bir elektrik çeliğinde, seçili bölgede net bir biçimde belli olan grainlerin, MA uygulanmasının öncesi ve sonraki durumları, hem Kerr mikroskobuyla hem de EBSD analizleriyle irdelenmiştir. Öncelikle, Kerr mikroskobuyla belirli bölgede, sıfır MA'da elde edilen yarı-statik Kerr görüntüsünden, G1, G2, G3 ve G4 olarak isimlendirilen dört farklı grain bölgesi belirlenmiştir. Bar tipi domainlere gömülü olan çivi-benzeri domainler, her ne kadar kristalin sapma açısı hakkında bilgi verse de, doğrultusal olarak sapma açısı, şekil - 3a'da verilen EBSD analiziyle birbirinde ayırt edilebilmiştir. Burada, yönelim dereceleri için hassasiyet sınırlaması konulmadı ̆̆ından dolayı, renk dağılımları, yönlendirilmiş bir çelik olduğunu ve sapma açılarının HD civarında olduğunu kanıtlamaktadır.

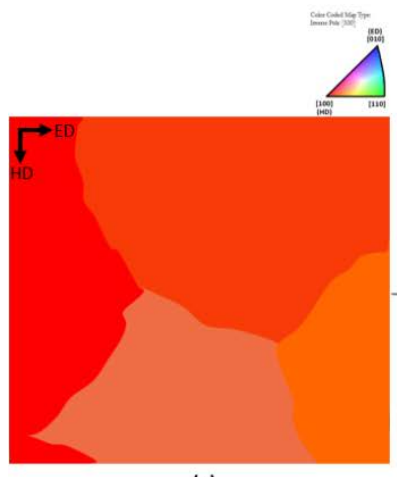

(a)

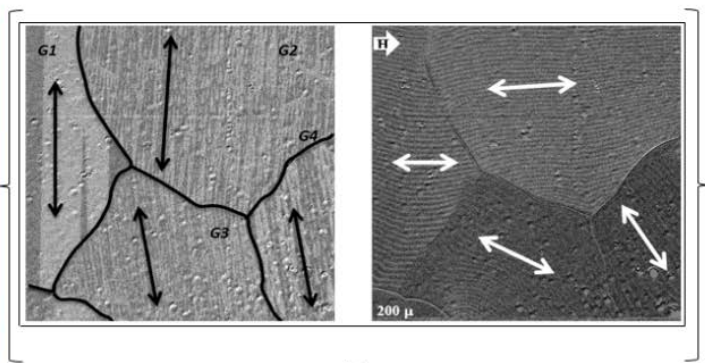

(b)

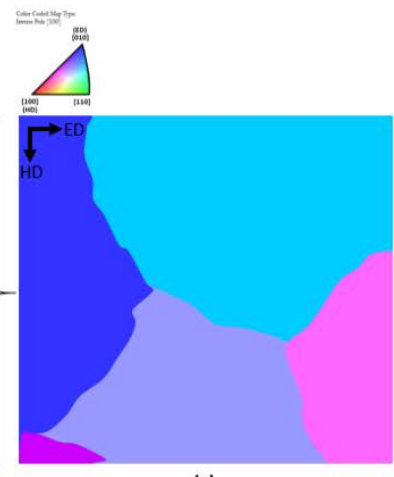

(c)

Şekil 3. Sıfır MA'da yönelim dışı sapma açılarının EBSD analiziyle (a) ve yarıkararlı Kerr görüntüsüyle (b) karşılaştırması. MA sonrasında ise Kerr görüntüsüyle

(b), EBSD analizi (c) yönelim dışı sapma doğrultularını, haritalandırma yoluyla göstermektedir. 
Öte yandan, MA uygulanması sonrasında da, malzeme manyetik doyuma ulaşmadığından dolayı grainler arasındaki yönelim kararsızlığı devam etmektedir (Şekil - 3b). Tüm grainler içerisindeki domain kümeleri, kararlı bir yönelime sahip olmasına rağmen, grainler arasındaki kararsızlık, halen kristal doğrultularının tamamen MA doğrultusunda olmadığının ispatıdır. Ayrıca, bu Kerr görüntüsünün, EBSD analizinde ise (şekil - 3c), (a)'dan farklı olarak, özellikle G3 ve G4'te yönelim dişı sapmanın ciddi boyutlarda olduğu görülmektedir. Bu durum beraberinde, grainler arasındaki manyetik yük yoğunluk farkından kaynaklı bir enerji birikmesinin olabileceği sorusunu getirir. Öyle ki, süreksiz mıknatıslanmaya sebep olabilecek sapmalar gösteren grain sinırlarına yaklaşıldığında, MA şiddetinin artmasıyla, yönelim dışı sapmalarda artış gözlemlenebilir [4]. Grain sınırlarında başlayan, nominal manyetik yük yoğunluğundaki farkl1lik,

$\sigma_{s}=\cos \emptyset_{1}-\cos \emptyset_{3}=2 \sin \left[\frac{1}{2}\left(\emptyset_{1}+\emptyset_{3}\right)\right] \sin \left[\frac{1}{2}\left(\emptyset_{1}-\emptyset_{3}\right)\right]$

eşitliğiyle, G1 ile G3 arasındaki sapma açılarına uyarlanmıştır. Burada, $\sigma_{s}$ manyetik yük yoğunluğunu, $\emptyset_{1}$ ve $\emptyset_{3}$, G1 ve G3 grainlerinin ortalama yönelim doğrultusu ile sinır normali arasındaki açı değerlerini ifade etmektedir. Şu açıktır ki, G1 ve G3 farklı sapma açılarına sahip olduğundan, $\sigma_{s}$ sıfır olmamalıdır. Bu durum, mikro manyetik olarak bölgede lokal bir enerji birikimi olduğunun da habercisidir. Aslında bu durumun en net göstergesi, tüm grainlerin sınırlarından merkezlerine doğru giderken domain desenlerinde bir dalgalanma olmasıdır. Böylelikle, kararlı domain dağılımı, daha yüksek MA uygulanmadan, mümkün olamamaktadır.
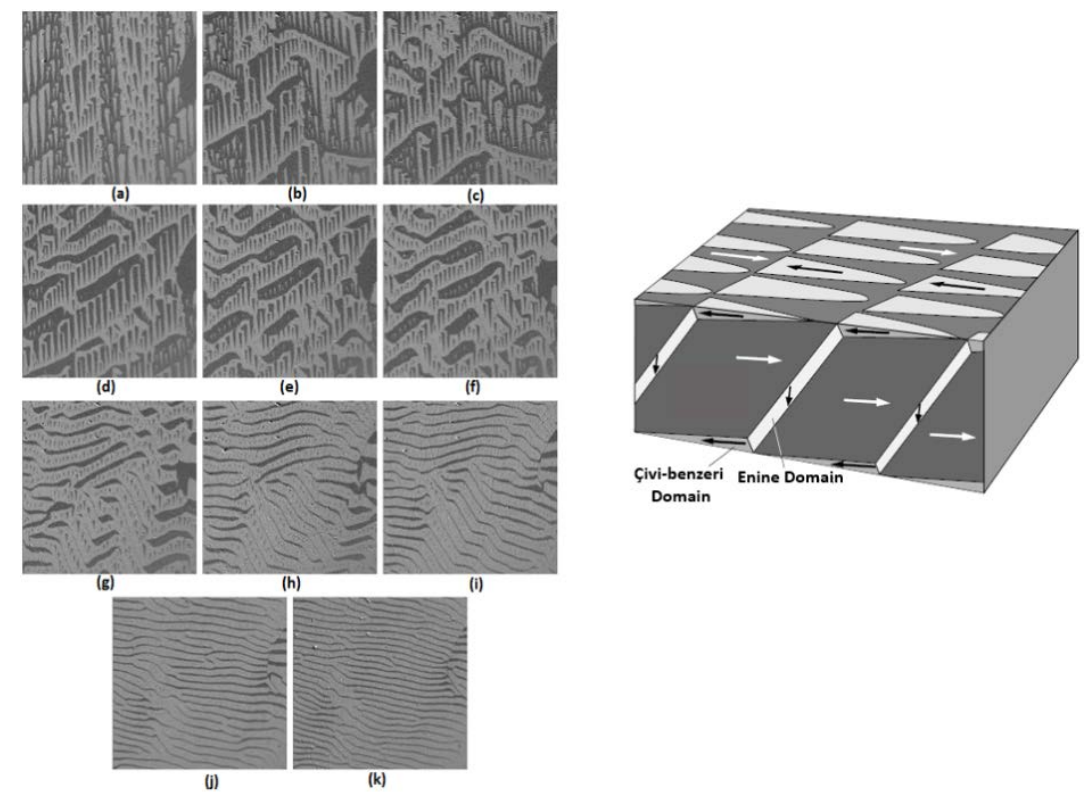

Şekil 4. Enine MA etkisi altında TD'nin evrilme süreçleri. (a) 0, (b) $50 \mathrm{~A} / \mathrm{m}$, (c) $70 \mathrm{~A} / \mathrm{m}$,

(d) $100 \mathrm{~A} / \mathrm{m}$, (e) $150 \mathrm{~A} / \mathrm{m}$, (f) $200 \mathrm{~A} / \mathrm{m}$, (g) $300 \mathrm{~A} / \mathrm{m}$, (h) $500 \mathrm{~A} / \mathrm{m}$, (i) $1 \mathrm{kA} / \mathrm{m}$, (j) 2 $\mathrm{kA} / \mathrm{m}$ ve (k) $3 \mathrm{kA} / \mathrm{m}$ MA uygulanarak elde edilen yüksek çözünürlüklü Kerr görüntüleri.

Öte yandan bölgede bulunan çivi-benzeri tamamlayıcı (supplementary) domainler (TD) de gözlenmiştir. TD, malzemenin yüzey ve iç bölgelerinde KME'den birkaç derecelik sapmalara bağlı olan gerilmeleri işaret eder. Söz konusu bölgede, grain içerisinde bu 
durum fark edilemese de, Şekil - 3b'de olduğu gibi birkaç graini içine alan bir bakış açısıyla bu farklılık gözlenebilir. Şekil - 4'te ise çok keskin ve net bir çivi benzeri domain dağılımının evrilme süreci verilmiştir. Sıfır MA'da (a)'da gözlenen yapılar, 100 A/m'lik enine MA etkisi altında, "tarak-benzeri" bir yapıya evrilirken (d ve e), uygulanan MA, 1 kA/m'ye çıkarıldığında, TD “dallanmış domainlere” (i-k) dönmeye başlamıştır. Başlangıçta elde edilen TD diziliminin yüzey ve içyapıdaki dağılımı, mıknatıslanma doğrultularıyla birlikte model olarak sağ tarafta verilmiştir [bu şekil [4]'ten alınmıştır].

$0.22 \mathrm{~J}_{\mathrm{s}}$ büyüklüğünde, HD’nin enine uygulanan MA sonrasında, yaklaşı $90^{\circ}$ dönme gerçekleştiren bir domaine ait eğri ve kutup diyagramları şekil - 5'te gösterilmiştir. Burada HD ve ED arasındaki anizotropi enerji farklılı̆̆ normalde, boyuna haddelenen malzemelerde ortaya çıkandan çok daha fazla bulunmuştur. Ancak şu bir gerçektir ki, boyuna KME'ye sahip bir elektrik çeliği, aynı doğrultu üzerinden MA'ya maruz bırakılırsa, domain yapıları kolaylıkla duvarları bertaraf edip, tek bir mıknatıslanma doğrultusunda doyuma ulaşacaktır (şekil - 1b). Ancak, bu çalışmada, spesifik bir uygulama olan enine MA uygulaması sonucunda, ortaya çıkacak anizotropi enerjisinin, malzemede domain diziliminin izin verdiği akı dağılımına etkisi incelenmektedir. Şekil - 5a'da, [100] doğrultusundaki KME'ye, [010] doğrultusunda, 0,1 $\mathrm{J}_{\mathrm{s}}$ ile 0,22 $\mathrm{J}_{\mathrm{s}}$ aralığında uygulanan MA yoğunluğu ile domain hareketleri incelenmiş ve dönme açısına göre bir eğri oluşturulmuştur. Buna ek, (b)'de (110) kristal düzleminde gerçekleşen bu dönme hareketinin, kutup diyagramındaki gösterimi de, ED'de ki, kristal anizotropinin etkisini gözler önüne sermektedir.

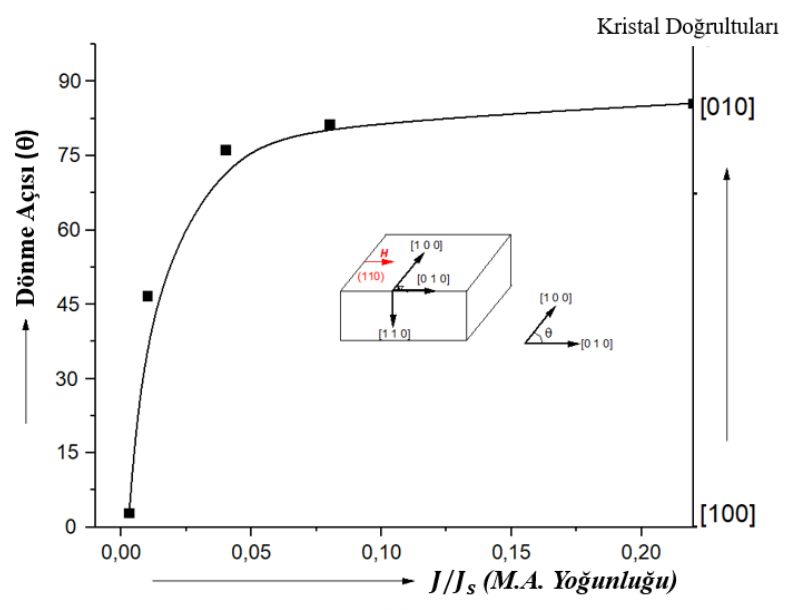

(a)

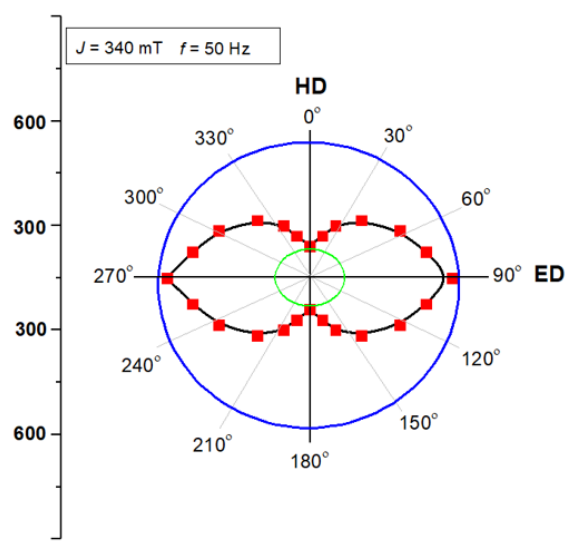

(b)

Şekil 5. Enine uygulanan MA'nın bir fonksiyonu olarak, domainlerin dönme açısı eğrisi (a) ve Kutup koordinatları gösterimi (b).

Böyle durumlarla, elektrik makinelerinin en önemli öğelerinden olan transformatörlerin çekirdek eklemlerinde (köşe bölgesi) sıklıkla karşılaşılabilir [1, 4]. Şekil - 6’da, böyle bir tek fazlı güç transformatör çekirdeğinin, köşe bölgesindeki akı dağılımı vektörel olarak simule edilmiştir. Aynı zamanda, Kerr görüntülerinde de bar tipi domainlerin, enine MA etkisi altında evrilme süreçleri verilmiştir. Simülasyonda gerçekleştirilen ve kırmızı kutucuklarla işaretlenen akı dağılımındaki akış şeması, enine bir domain dağılımının gerekliliğini ortaya koymaktadır. Ayrıca, Kerr görüntülerinin başlangıcında, KME doğrultusunda uzanan yaklaşık iki ve yarım domain deseni (ortalama 30 mikron genişliğinde), 0,22 $\mathrm{J}_{\mathrm{s}} \mathrm{MA}$ yoğunluğunda, yirmi civarında domain desenine evrilmiştir. 
Böylelikle manyetik kristal anizotropide ve dolayısıyla koersivitede ciddi bir artış oluşmuştur. Buna karşın malzemenin bağıl ve mutlak geçirgenliklerinde ise azalma gözlenmiştir. Bunun yanı sıra, uygulanan MA yoğunluğunda oluşan domain diziliminde ciddi dalgalanmalar görülmektedir. Manyetik domainlerin birim alandaki sayısının, sıfır MA'dakinin yaklaşık 15 katına çıkması, oluşan bu düzensiz dağılımın sebeplerindendir.

Manyetik kristal anizotropide, uygulanan MA doğrultusuna bağlı olarak görülen artış, mıknatıslanma eğrilerinin eğiminden de anlaşılabilir. Bunu göstermek için şekil - 7'de, 2-boyutta eksenel simetrik olarak manyetik akı yoğunluğu simule edilen bir fazlı basit bir trafo nüvesine bağlanan algılayıcı (arama) bobinleri ile deneysel olarak histerezis eğrileri elde edilmiştir. Araştırmanın başından beri temel unsurlarını oluşturduğumuz, eklem bölgelerdeki akı dağılımının $90^{\circ}$ kadar saptırılması ve bölgede lokal olarak anizotropiyi indüklemesi, bu çalışmayla da gösterilebilmiştir. Histerezis eğrileri, genellikle bir elektronik integratör vasıtasıyla oluşturulduğundan, eğrideki eğimin doğrudan, nicel olarak malzemede depolanan anizotropi enerjisine uyarlanması oldukça zordur. Ancak, şekil - 7'de, yukarıdan aşağıya, eklem bölgesinde, çekirdeğin bir kolunda (HD'de uzanan) ve diğer eklem bölgesinin civarında elde edilen histerezis eğrileri nitel olarak akı dağılımındaki sapmaları yorumlaya imkan tanır.

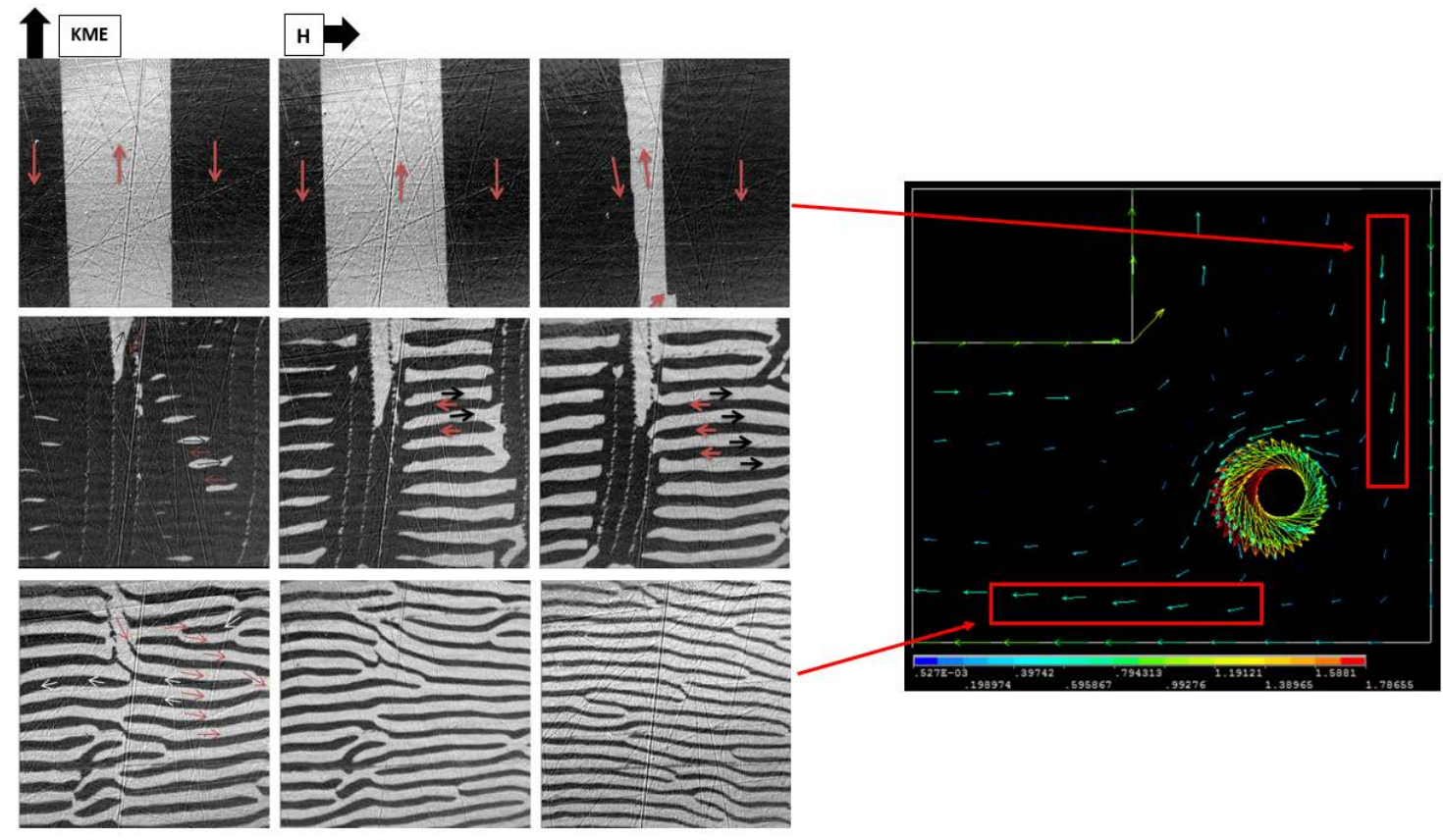

Şekil 6. Levha (bar) benzeri domainlerin, 0 ile $0.22 \mathrm{~J}_{\mathrm{s}}$ aralığında uygulanan MA yoğunluğu etkisi altında evrilme süreçleri ve mıknatıslanma doğrultularının gerçek bir benzetim çalışmasıyla karşılaştırılması.

Eklem bölgesi bulunmayan ve boyuna haddelemiş lamine elektrik çeliklerinde elde edilen güç kayıpları ve buna bağlı güç kaybı bileşenleri, kare tipi basit trafo çekirdeklerinin tek bir katmanıyla karşılaştırıldığında, ciddi farklar ortaya çıkmaktadır. Bunun en önemli sebeplerinin başında, eklem bölgelerinde ortaya çıkan uyarılmış anizotropi yoğunluğunun oluşmasıdır. Öyle ki, araştırma unsurlarımızdan olan AK'nın, koersivite $\left(\mathrm{H}_{\mathrm{c}}\right)$, kristal anizotropi $\left(\mathrm{E}_{\mathrm{a}}\right)$ ve manyetik iç ve yüzey gerilmeleri $\left(\mathrm{E}_{\mathrm{ms}}\right)$ gibi manyetik özelliklere bağlı olarak değiştiği bilinmektedir. Buna göre, eklem bölgelerinin, malzemenin kristal anizotropisinden dolayı, malzemede oluşturduğu enerji birikimi (1sınma ya da gürültü oluşturabilir) AK için ciddi bir kaynak oluşturur. 


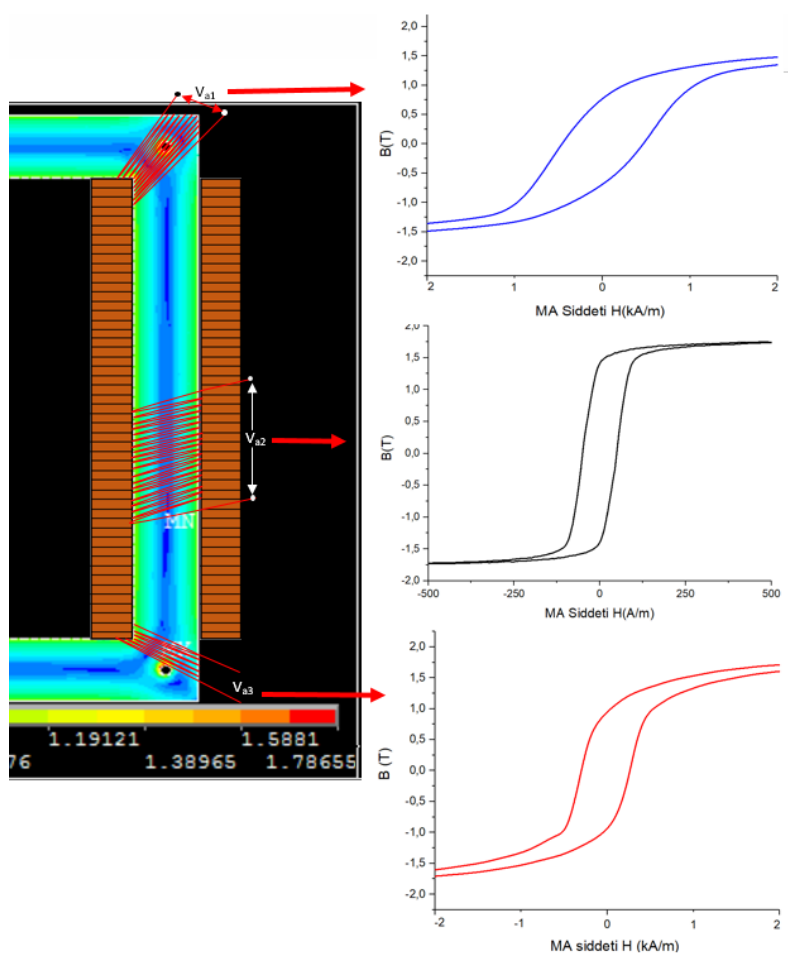

Şekil 7. Kare tipi bir transformatör çekirdeğinin üç farklı noktasına bağlanan arama bobinleriyle elde edilen histerezis eğrileri

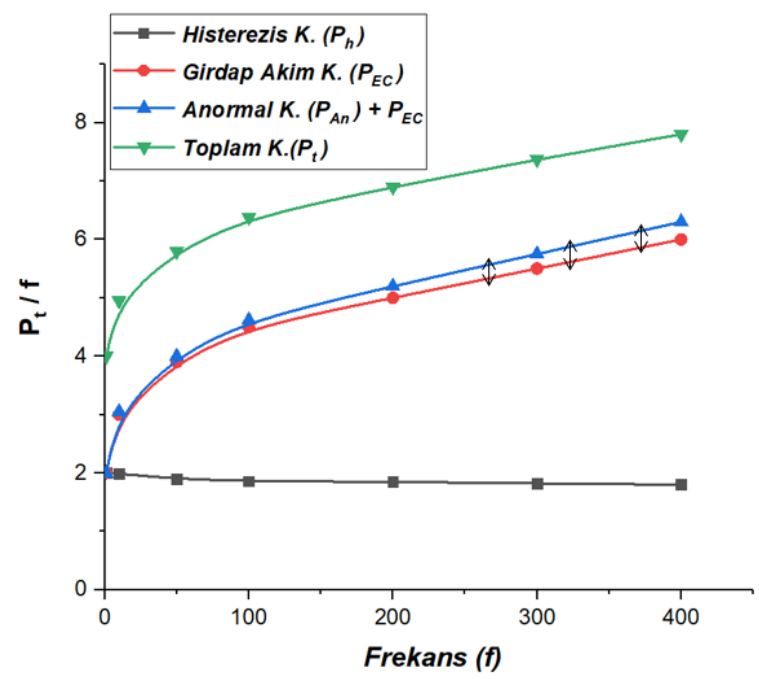

(a)

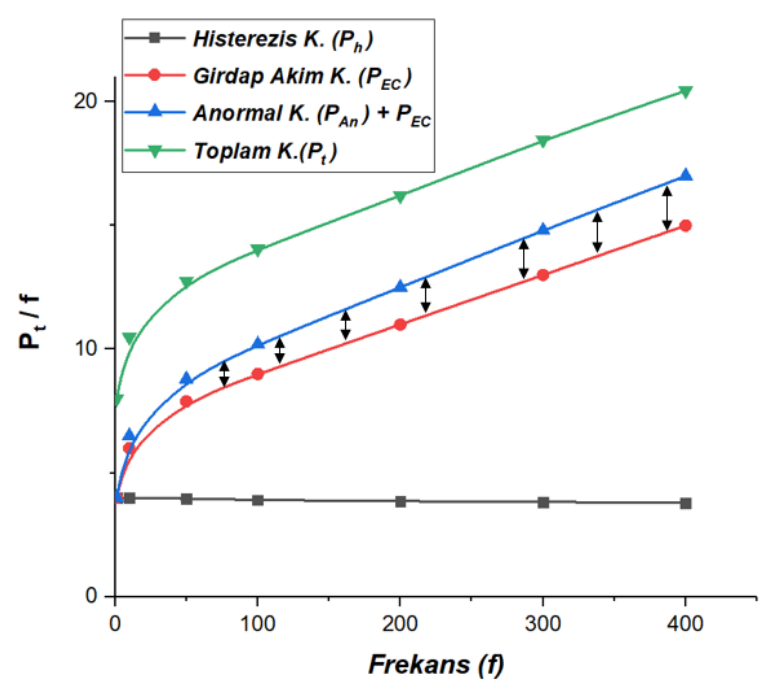

(b)

Şekil 8. Çalışma frekansının bir fonksiyonu olarak tek saçtan alınan toplam güç kaybı ölçümleri (a) ve tek katmanlı (laminasyonlu) üretilen trafo nüvesi için ölçülen güç kaybı ölçümleri (b). Güç kaybı bileşenlerinden $\mathrm{P}_{\mathrm{t}}$, her iki numune için de ölçülmüş; $\mathrm{P}_{\mathrm{EC}}, \mathrm{P}_{\mathrm{An}}$ ve $P_{h}$ ise ilgili bağıntılarla hesaplanarak bulunmuştur.

Bu bağlamda, Şekil - 8'de, hem Epstein geometrisine sahip tek saçtan (a) hem de dört eşdeğer tek saçtan oluşturulmuş bir trafo nüvesinden (b), güç kaybı ölçümleri alınmıştır. Aynı zamanda, elde edilen güç kayıpları, (1) ve (2) eşitlikleri kullanılarak histerezis ve girdap akımı kayıpları elde edilmiştir. Ölçülen toplam güç kayıpları ile bu kayıp 
bileşenleri çıkarıldığında, AK bileşenleri elde edilebilmiştir. Her iki güç kaybı bileşen eğrilerinde de, hesaplanan AK bileşeni, histerezis kayıp bileşenleri ile karıştırılmaması için klasik girdap akımı kaybı bileşeni ile toplanarak verilmiştir. Böylelikle, $\mathrm{P}_{\mathrm{EC}}$ ve $\mathrm{P}_{\mathrm{AK}}+\mathrm{P}_{\mathrm{EC}}$ arasında kalan bölgeler, AK'nın etkisinin eklem bölgelerinden dolayı nasıl arttığını göstermektedir. Frekansın bir fonksiyonu olarak elde edilen eğrilerde, $400 \mathrm{~Hz}$ üst limit olarak tutulmuştur. Bunun sebebi, bu frekans değerinin üstünde, çok ciddi harmonikler oluşması ve her iki yapıda da ısınmalar meydana gelmesidir.

\section{Sonuçlar}

AK değerleri, aynı zamanda, Kerr görüntülerinden ölçülen dönme açıları ve uygulanan MA yoğunluğunun büyüklüğüne göre, (4) ve (5) eşitlikleriyle karşılaştırılmıştır. Ölçülen ve hesaplanan değerler arasında \%58 civarında bir uyum olduğu gözlenmiştir. $\mathrm{Bu}$ oran, nicel olarak sadece yüzey domain duvar hareketine göre ve sadece uyarılan kristal anizotropi enerjisinin varlığına dayanılarak hesaplanmıştır. Ayrıca manyetik gerilme enerjisi, dönme (exchange) etkileşim enerjisi, kaçak alan enerjisi, dış alan (Zeeman) enerjisi ve malzemenin içyapısındaki (Kerr mikroskobuyla gözlemlenemeyen) kristal anizotropi enerjisi gibi domain yapısına bağlı enerji dengeleri de bulunmaktadır. Bu mikro manyetik enerji terimleri de hesaba katıldığında, AK ile ilgili net bir sayısal tanımlama yapmak mümkün olabilir.

\section{Kaynaklar}

[1] Tang, Q., Guo, S. ve Wang, Z., Magnetic flux distribution in power transformer core with mitred joints, Journal of Applied Physics, 117, 17D522, (2015).

[2] Vorperian, V., A fractal model of anomalous losses in ferromagnetic materials, 23rd Annual IEEE Power Electronics Specialists Conference (PESC '92), IEEE Power Electronics, 2, 1277-1283, Toledo, (1992).

[3] Landgraf, F. J. G., Teixeira, J.C., Emura, M., de Campos, M.F. Muranaka, C.S., Separating Components of the Hysteresis Loss, Materials Science Forum, 302-303 440-445, (1999).

[4] Hubert, A. ve Schäfer, R., Magnetic Domains, 3rd ed. Berlin, Germany:Springer, (1998).

[5] Cullity, B.D., Graham, C.D., Introduction to Magnetic materials, IEEE Press, Wiley, 2nd edition, New Jersey, USA, (2009).

[6] O. Perevertov, O., J. Thielsch, J. ve Schäfer, R., Effect of applied tensile stress on the hysteresis curve and magnetic domain structure of grain-oriented transverse Fe-3\%Si steel, J. Magn. Magn. Mater., 385, 358-367, (2015).

[7] Moses, A. J., Derebasi, N., Loisos, G. ve Schoppa, A., Aspects of the cut-edge effect stress on the power loss and flux density distribution in electrical steel sheets, J. Magn. Magn. Mater., 215, 690-692, (2000).

[8] He, Y. ve Hilinski, E.J., Texture and magnetic properties of non-oriented electrical steels processed by an unconventional cold rolling scheme, J. Magn. Magn. Mater., 405, 337-352, (2016).

[9] Koike K., Magnetic Domain Imaging with Spin-Polarized SEM, (Xu Y., Awschalom D., Nitta J. - eds.) Handbook of Spintronics. Springer, Dordrecht (2016).

[10] Duc-The Ngo and Luise Theil Kuhn, In situ transmission electron microscopy 
for magnetic nanostructures, Adv. Nat. Sci: Nanosci. Nanotechnol. 7, 045001, 1-16, (2016).

[11] Iwata, K., Arai, S. and Ishiyama, K., Calculation of Basic Domain Width Considering Lancet Domains in (110)[001]Fe3\%Si, IEEE Transactions on Magnetics, 50, 2, 353-356, (2014).

[12] Tanaka, T., Matsuzaki, J., Kurisu, H. ve Yamamoto, S., Relationship Between Coercivity and Magnetic Domain Structure for Permalloy Thin Film, Transactions of Materials Research Society of Japan, 3, 4, 407-409, (2009).

[13] Bozorth, R.M. ve Walker, J.G., Magnetic Crystal Anisotropy and Magnetostriction of Iron-Nickel Alloys, Physical Review, 89, 624, (1953).

[14] Schäfer, R., Investigation of domains and dynamics of domain walls by the magneto-optical Kerr effect, Handbook of Magnetism and Advanced Magnetic Materials, vol. 3, H. Kronmüller and S. Parkin, Ed. Hoboken, NJ, USA: Wiley, (2007).

[15] Gunes, T., Schäfer, R. ve Derebasi, N., Quantitative Analysis of Magnetic Field Distribution Around Circular Non-Magnetic Region in Grain-Oriented Fe-3\%Si Steel, IEEE Transactions on Magnetics, 54, 2, 1-8, (2018).

[16] Betz, B., Rauscher, P., Siebert, R., Schaefer, R., Kaestner, A., Van Swygenhoven, H., Lehmann, E., Grünzweig, C., Visualization of Bulk Magnetic Properties by Neutron Grating Interferometry, Physics Procedia, 69, 399-403, (2016).

[17] Perevertov, O. ve Schäfer, R., Influence of applied tensile stress on the hysteresis curve and magnetic domain structure of grain-oriented $\mathrm{Fe}-3 \% \mathrm{Si}$ steel, Journal of Physics D; Applied Physics, 47, 18, 185001, (2014). 